\title{
La propuesta migratoria del presidente Bush: naturaleza, viabilidad y pertinencia
}

\section{Relatoría de María Adela Angoa*}

Con el propósito de generar un espacio de reflexión y de discusión sobre la naturaleza de la propuesta migratoria del presidente Bush y sus efectos tanto en nuestro país como en Estados Unidos, El Colegio de México y El Colegio de la Frontera Norte organizaron el foro "La propuesta migratoria del presidente Bush: naturaleza, viabilidad y pertinencia", 1 en el que participaron diversos actores involucrados en este proceso: académicos estudiosos del tema migratorio procedentes tanto de México como de Estados Unidos, sociedad civil representada por organizaciones no gubernamentales también de ambos países y funcionarios del gobierno mexicano.

En cuanto al grupo de académicos, se contó con la presencia de Francisco Alba, Gustavo Verduzco y Manuel Ángel Castillo (coordinador del foro), de El Colegio de México; Jorge Santibáñez y Rodolfo Cruz, de El Colegio de la Frontera Norte; Rafael Fernández de Castro, del Instituto Tecnológico Autónomo de México; Manuel García y Griego, de la Universidad de Texas, Arlington, y Andrés Jiménez, del Public Policy Institute de la Universidad de California en Berkeley. Asistieron también Katherine Culliton, del Mexican American Legal Defense and Educational Fund (MALDEF) y Fabiénne Venet, de la organización Sin Fronteras. Participaron además los funcionarios Magdalena Carral, del Instituto Nacional de Migración; Gerónimo Gutiérrez, subsecretario para Asuntos de América del Norte de la Secretaría de Relaciones Exteriores, y Elena Zúñiga, secretaria general del Consejo Nacional de Población (Conapo).

Los participantes del foro reflexionaron sobre cuestiones tales como: ¿qué elementos deben considerarse para que esta propuesta resulte lo más conveniente para México?, ¿de qué manera constituye una oportunidad, aunque inicial y con deficiencias, para futuras negociaciones entre México y el país vecino?, ¿puede el gobierno mexicano insertarse de manera acrítica en dicha propuesta?

* Estudiante del doctorado en Estudios de Población del Centro de Estudios Demográficos y de Desarrollo Urbano de El Colegio de México.

${ }^{1}$ Dicho foro se efectuó el 21 de enero de 2004 en las instalaciones de El Colegio de México. 
Los académicos hicieron un recuento de los aspectos sobresalientes de la propuesta del presidente Bush enunciada el 7 de enero de 2004: está elaborada esencialmente para reclutar trabajadores migratorios extranjeros admitidos como no residentes, con permiso para trabajar por tres años en Estados Unidos (y con la posibilidad de renovarlo por tres años más); está encaminada a solucionar el problema de los empresarios estadunidenses que ofrecen empleos con salarios y condiciones que no aceptan los trabajadores nativos ni los inmigrantes autorizados, por lo que se recurre a inmigrantes que puedan llenar estas vacantes; impulsa incentivos para que los trabajadores no permanezcan en Estados Unidos, mediante estímulos financieros en sus países de origen; reconoce la necesidad de controlar el ingreso de trabajadores extranjeros a Estados Unidos, así como la de proteger sus derechos laborales pero no especifica mediante qué mecanismos.

Los académicos coincidieron en señalar tres puntos desfavorables de la propuesta ya que afectan directamente los reclamos de México en el terreno migratorio: ésta no contempla la legalización de los indocumentados residentes en Estados Unidos; no fue formulada únicamente para los mexicanos, sino para todos los inmigrantes que arriban a dicho país; y aún no ha sido presentada al Congreso estadunidense, lo que la convertía hasta ese momento en un discurso con buenas intenciones.

Después de discutir la propuesta, los participantes del foro unificaron sus consideraciones sobre las razones por las cuales se emitió:

1) Se trata de una propuesta que favorece la entrada de trabajadores inmigrantes temporales que puedan ocupar las plazas ofrecidas por los empresarios estadunidenses y que los nativos no desean. No contempla la regularización, la amnistía o los programas braceros.

2) A raíz de los atentados del 11 de septiembre, privilegia razones de seguridad nacional como el mejor control de las fronteras mediante una lógica de "fichaje" (quién entra y quién sale del país). Incluye una forma indirecta de "sacar de las sombras" o de dar un estatus legal a aproximadamente 12 millones de trabajadores inmigrantes indocumentados.

3) Sin contraponerse con los motivos anteriores, la propuesta es vista como una maniobra electoral para lograr el voto latino pues surge en un contexto político electoral, en el que el presidente Bush desarrolla su campaña de reelección. 
Sobre el impacto de las propuesta en la mejoría de las relaciones entre México y Estados Unidos en el terreno migratorio, las opiniones de los especialistas se dividieron. Mientras algunos académicos ven la propuesta como una ventana de oportunidades para lograr un acuerdo migratorio entre el país vecino y el nuestro, otros recomiendan actuar con más cautela.

Entre las razones que alientan a considerar ventajoso el plan propuesto por el presidente Bush, los especialistas (tanto académicos como representantes de las $\mathrm{ONG}$ ) mencionaron dos que insólitamente han sido expresadas por la Casa Blanca: 1) el reconocimiento del papel fundamental que los inmigrantes juegan en la economía norteamericana; 2) la ineficiencia e insuficiencia del sistema migratorio estadunidense para controlar los flujos de inmigración y atender sus consecuencias en dicho país, lo que obliga a plantear una reforma migratoria integral acorde con las exigencias actuales.

Entre las razones aducidas por los especialistas para considerar dudosa la viabilidad de que la propuesta migratoria permita negociar mejores oportunidades para los inmigrantes mexicanos en Estados Unidos está que el tema migratorio es secundario para Estados Unidos y que, dado que la propuesta no constituye un acuerdo de legalización de los migrantes indocumentados, el interés del gobierno estadunidense es fomentar la migración circular mediante empleos temporales con incentivos para que los trabajadores retornen a sus países de origen. A juicio de los académicos, estas medidas sólo resuelven el cruce fronterizo de algunos inmigrantes que llegan a competir con los que ya residen en ese país, y que pueden obtener la legalización. Además, aumenta la posibilidad de que una vez vencido el plazo de la visa temporal, los inmigrantes puedan ser fácilmente localizados y se les impida permanecer en Estados Unidos.

Los especialistas también manifestaron que la aprobación de la propuesta sería una decisión unilateral, pese a que afecta a los distintos países de procedencia de los inmigrantes; por ello consideraron que refleja que Estados Unidos no está dispuesto a negociar acuerdos migratorios con ninguna nación.

Los académicos mexicanos manifiestaron que la propuesta del presidente Bush ha generado incertidumbre respecto a la consecución de relaciones favorables para los inmigrantes mexicanos en Estados Unidos. Explicaron que en el año 2001 las negociaciones migratorias de ambos países estaban enmarcadas en un proyecto binacional y bilateral cuya meta era profundizar la integración en 
América del Norte mediante el TLC, pero que a raíz de los acontecimientos del 11 de septiembre, hubo un cambio radical en las relaciones bilaterales entre México y Estados Unidos: después de esta fecha el proyecto desapareció, y de los puntos que se inscribieron en la agenda de negociaciones en 2001, la propuesta estadunidense sólo dio respuesta parcial al reclamo del gobierno mexicano para la legalización de los mexicanos en Estados Unidos mediante el establecimiento de un programa de trabajadores temporales y el aumento del número de visas para mexicanos. Los especialistas estimaron que el lapso permitido de estancia de los trabajadores migratorios (máximo seis años) sólo pospone el problema pues no resuelve qué va a pasar con ellos después de que las visas temporales caduquen. Los académicos añadieron que la respuesta mexicana a esta propuesta (gubernamental y no gubernamental) no debe crear falsas expectativas pues su instrumentación puede durar años, y exhortaron a los funcionarios públicos a entender que el contexto de la relación México-Estados Unidos ha cambiado y que las estrategias del cabildeo no necesariamente deben ceñirse a una relación bilateral.

Otros académicos estuvieron de acuerdo en que la propuesta del presidente Bush de ofrecer empleos temporales debe ser motivo de alerta para los mexicanos que intenten ingresar a este programa, pues Estados Unidos sólo ofrecerá trabajos precarios y de baja remuneración y ninguna opción para adquirir la permanencia definitiva en ese país. También consideraron que la creación del programa temporal de inmigrantes ha originado falsas expectativas, sobre todo por la forma en que ha sido manejada en los medios de comunicación, donde se alimenta la idea de que existen ofertas de trabajo en el país vecino, que existe la opción de regularizar el estatus legal de los indocumentados, y de que se puede cruzar libremente hacia dicho país. Estas falacias, advirtieron los investigadores, contribuirán a crear riesgos en la frontera entre México y Estados Unidos, y ponen en peligro a miles de mexicanos, sobre todo si se considera que el asegurar cada vez más la frontera es el único punto de los acuerdos migratorios del año 2001 que sí se ha respetado.

En el intercambio de opiniones de los participantes del foro se criticó que la iniciativa del presidente Bush es pobre en cuanto no trata aspectos tales como el acceso a la residencia, a la nacionalidad estadunidense, y a cuestiones como la reunificación familiar, entre otros. También se criticó la pasividad del gobierno mexicano en temas como la circularidad migratoria y el trabajo temporal, y se sugirió 
el involucramiento de otras secretarías de gobierno como la de Desarrollo Social, para supervisar, defender y proteger los derechos de los migrantes. Los analistas subrayaron la necesidad de contemplar alianzas de México con los países de Centroamérica o de América Latina en la negociación migratoria con Estados Unidos.

Por otra parte, otros especialistas, junto con el representante de la ONG en Estados Unidos, consideraron que la propuesta migratoria de Bush es viable y puede favorecer la mejoría de las condiciones de los migrantes mexicanos en Estados Unidos, ya que conlleva oportunidades para negociar el ansiado estatus legal de los inmigrantes mexicanos residentes en dicho país y de sus descendientes. Sostuvieron que esta propuesta se añade a otras que intentan reformar la legislación migratoria en Estados Unidos, pero que hasta el momento no han progresado debido a la ausencia de una coalición política bilateral y a las contradicciones de los políticos estadunidenses en este terreno. Por ello, los especialistas y el representante de la onG mencionada exhortan a la sociedad civil tanto de México como de Estados Unidos a crear una coalición política para la resolución de problemas migratorios en ambos congresos mediante la formación de grupos de presión bilaterales o binacionales, que puedan actuar en sus propios países como actores individuales, y al mismo tiempo colaborar conjuntamente en un proyecto de reforma migratoria.

Para algunos otros académicos mexicanos, la propuesta del presidente de Estados Unidos abre una rendija de oportunidad para negociar un acuerdo migratorio con dicho país. La diplomacia mexicana — sostuvieron-, debe "cabildear" en Estados Unidos y buscar alianzas con aquellos que pueden ser aliados "naturales" (los grupos proinmigración o los empleadores estadunidenses que necesitan de la mano de obra migrante) y con los aliados "potenciales" (asociaciones latinas, sindicatos de trabajadores); para ello es menester añadir demandas tales como la legalización del estatus de indocumentado. De igual manera recalcaron que la propuesta de Bush recae en un contexto en donde el debate migratorio se ha politizado enormemente, de tal forma que su omisión en la campaña por la presidencia estadunidense resultaría en una disminución de votos para el Partido Republicano, al cual pertenece el actual mandatario.

Otros académicos participantes coincidieron en que la propuesta de Bush genera oportunidades para negociar un acuerdo migratorio, debido especialmente a que la migración hacia Estados Unidos continuará mientras nuestro país no posea los mecanismos para rete- 
ner la mano de obra joven que se incorpora al mercado de trabajo. Por ello consideraron que el intento por ordenar el flujo migratorio centrándose en los trabajadores temporales constituye un avance desde cualquier punto de vista; pero, puntualizaron, pensar que dicha propuesta es la solución al problema de la migración a Estados Unidos es una equivocación pues la oportunidad es expresada únicamente en la estrategia de Bush para evitar la residencia permanente de inmigrantes en su país; la intención de devolverle la circularidad a un proceso que inicialmente la tenía y que se rompió con el control más severo de la frontera; la modificación de los mercados de trabajo norteamericanos (no únicamente estacionales), y la falta de expectativas económicas de los inmigrantes a su regreso a México.

Para garantizar que los efectos de la propuesta beneficien a los migrantes temporales, además del "cabildeo" en Estados Unidos, México podría generar programas de protección y orientación para que los migrantes se vayan en condiciones adecuadas, en los que podrían participar la Secretaría del Trabajo y Previsión Social, y la de Desarrollo Social. De igual forma advirtieron que en caso de ser aprobada por el Congreso estadunidense, la propuesta de Bush tomará más de dos o tres años en ser ejecutada, y no necesariamente contribuirá a la legalización de los mexicanos que ya residen en la Unión Americana.

Por su parte, los representantes del gobierno mexicano coincidieron en afirmar que la iniciativa del presidente Bush inclinará la balanza en la consecución de un acuerdo migratorio conveniente para ambos países pues constituye un primer paso para vigorizar y estimular el debate sobre la reformulación del sistema migratorio vigente en Estados Unidos; en este contexto consideraron ventajosa la estrecha relación bilateral lograda entre México y Estados Unidos durante el gobierno del presidente Vicente Fox. Igualmente señalaron que la propuesta es creativa y que aborda diferentes aristas del fenómeno migratorio no sólo mediante el esquema de trabajadores temporales sino que intenta normalizar y legalizar el estatus migratorio de las personas que se encuentran allá, así como ampliar y modernizar los mecanismos para que en el futuro los mexicanos que decidan migrar puedan hacerlo de manera segura y legal. Para lograr estas metas, la estrategia del gobierno mexicano se basará en el trabajo de los canales diplomáticos en el Congreso de Estados Unidos, con el presidente Bush e incluso con los mismos empleadores, mediante el diálogo y la concertación. De manera específica, el subsecretario para América del Norte de la Secretaría de Relaciones Exteriores, Gerónimo 
Gutiérrez, planteó diez puntos de análisis para avanzar a corto plazo en la agenda migratoria con Estados Unidos:

1) Facilitar y hacer más eficiente el acceso al programa migratorio de empleo temporal en los términos planteados hasta el momento.

2) Delinear las modalidades de renovación de los periodos y su du-ración.

3) Definir el proceso para acceder a la residencia permanente y eventualmente a la ciudadanía.

4) Definir el tratamiento que podría darse a las personas autoempleadas.

5) Definir los criterios que garanticen la unidad familiar de los migrantes.

6) Definir el tratamiento que podrían tener las personas que han sido sujetas a un proceso de repatriación administrativa.

7) Emitir disposiciones que garanticen la igualdad de derechos laborales.

8) Acelerar y facilitar la adquisición de la residencia permanente a la gente que se encuentra en dicho proceso, a fin de abrir espacios para nuevas solicitudes desde este programa.

9) Delinear las modalidades y los espacios para acordar bilateralmente algunos de los aspectos de un programa que prosperará eventualmente con estas características.

10) Acordar los tiempos de implementación que tendría la legislación, en caso de que fuera aprobada.

Así, en este debate se evidenciaron algunas coincidencias en cuanto a las estrategias de acción para negociar condiciones más favorables para los inmigrantes mexicanos en Estados Unidos, tales como el "cabildeo" del gobierno mexicano en ese país y también en México, el impulso y fortalecimiento de alianzas o "concertacesiones" con los actores directamente implicados de ambos países y de América Latina (empleadores, inmigrantes), y la participación más directa no sólo de la Secretaría de Relaciones Exteriores, sino de otras como la de Desarrollo Social, y la de Trabajo y Previsión Social en la protección y salvaguarda de los derechos y bienestar de los inmigrantes mexicanos en Estados Unidos.

No obstante, los resultados también revelan la enorme complejidad del entramado de factores que inciden en las negociaciones del acuerdo migratorio, factores que dependen de los acontecimientos de orden mundial, así como también de las distintas evaluaciones de los actores directamente implicados en este campo: el gobierno, los académicos y la sociedad civil. 